\title{
A Study of Water-mist Recirculation System From Scale Kitchen Hood Ventilation
}

\author{
N. A. Nor Salim ${ }^{1}$, Norzelawati Asmuin ${ }^{2}$, M. A. Ahnaf Muslim³ , M. Farid Sies ${ }^{4}$, \\ A. Syakir M.Jamil ${ }^{5}$, M. R. Pairan ${ }^{6}$ \\ 1,2,3,4,5,6 Industrial Environment Engineering Research Group (IERG), \\ Centre for Energy \& Industrial Environment Studies (CEIES), \\ Universiti Tun Hussein Onn Malaysia (UTHM), 86400 Parit Raja, Johor, Malaysia \\ 1,2,3,4,5,6 Universiti Tun Hussein Onn Malaysia (UTHM), 86400 Parit Raja, Johor, Malaysia \\ ${ }^{1}$ adrian@uthm.edu.my \\ 2norzela@uthm.edu.my \\ 3ahnafamirmuslim@gmail.eom
}

\begin{abstract}
Water-mist spray was installed in several heavy-duty commercial kitchen hood ventilation (KHV) systemsfor grease emission control and safety purpose. Unfortunately, the water-mist process increased the water consumption, which is a part of the operational cost to the user. The aim of this research is to analyzethe water-mist spray characteristics with different fluid properties. The fluid properties are dependent on recycled water-mist wastewater quality. The 8 cycles of wastewater sample was collected from the experimental work at each cycle of 30 minutes cooking loads and the fluid properties was determinedusing viscometer and analytical balance. Thus, the experimental workwas conductedusing scale water-mist kitchen hood ventilation system.Simulation works are performed using Computational Fluid Dynamics (CFD) to determine the water-mist spray characteristics. The inlet watermist pressure studied in this research is 1.67 bar. As the number of cycle increased the percentage of fat, oils and grease (FOG) increased. The streamlinevelocity atnozzle inlet and outlet was compared between experimental and simulation. The highest outlet velocity was recorded from experimental and simulation is from fresh water (at 0 cycle) $10.937 \mathrm{~m} / \mathrm{s}$ and $10.610 \mathrm{~m} / \mathrm{s}$ respectively. The water-mist spray activation at 8 cycles shows the lowest outlet velocity is $10.767 \mathrm{~m} / \mathrm{s}$ from experimental and $10.434 \mathrm{~m} / \mathrm{s}$ from simulation. The percentage of absolute error of outlet velocity between experimental and simulation at 0 cycle (freshwater) is $2.99 \%$ which is the lowest among the cycles. The highest absolute error is $3.093 \%$ was recorded at nozzle outlet at cycle 8 (WW8).
\end{abstract}

Keywords-water-mist, recirculation, Kitchen hood, CFD, Kitchen Hood Ventilation (KHV)

\section{INTRODUCTION}

In heavy-duty cooking appliances such as a charcoal and char broilers deals with high heat loads with high temperatures inside the ductwork and produce large amount of FOG (Fats, Oils, and Grease). Grease deposits combined with high temperatures created during the cooking process are potentially cause explosive cocktails inside the kitchen hood ventilation system.Grease emission from typical cooking process consists of particulate and vapor [1] and enters the kitchen ventilation system. The commercial kitchen hood ventilation system must comply with NSPA 96 standard, which regular maintenance is required to clean the plenum, grease filter and ducting system from the grease deposited[2].

Cold-mist spray system in several heavy-duty kitchen hood canopies are installed to control efficiently the emissions produces from cooking process and for safety purpose. Cold water is used in the cold mist system and work as mist curtain inside the exhaust plenum of the canopy. The smokes where generated by the heavy-duty cooking appliances is forced to pass through the mist curtain. The mist curtains capture the airborne particles and part of the odors and finally conveyed to the drain. This is one of the methods used to filter FOG and to reduce the temperature from the air stream. The principle of this system is that cooking smokes that contains vapor entering the canopy. The vapor passes through the cold mist spray which causes the grease particles to drop in temperature, solidify, increase in size and drop to a drainage trough from which they are flushed to drain. Cold-water mist also functions as spark arrester and as an air cooler where to reduce the fire risks propagate in the ductwork.

In this research, a recirculation system for cold-mist process will be adopted to a scaled kitchen hood plenum. A strainer will be added and installed to the water-mist recirculation system to filter the wastewater before recirculate to the system. The nozzle $1 / 8 \mathrm{KSJB} 0.5$ flat fan spray was selected as water-mist spray nozzles. The spray characteristic was determined from ANSYS CFD simulation analysis and the fluid properties were determined from wastewater samples collected during experimental investigation. 


\section{LITERATURE REVIEW}

Majority of cooking operation especially in commercial kitchens generate emission and particulate matter that significantly effect to human health and reducing the air quality. Cooking-particulates are emitted from small scales food outlets in the form of smoke and fumes from barbecuing, roasting, and wood-fired cooking [3][4][7].

Some wood-fired pizza ovens use gas for cooking with a small wood fire to add flavour. The gas fire probably reduces odours but not particles in the wood-smoke. The particles consist of partially burnt fats emitted from the cooking meat and wood-smoke. These are known to contain materials detrimental to health such as polyaromatic hydrocarbons (PAHs) and fine particles $\left(\mathrm{PM}_{2.5}\right)[7][8]$.

Studies on air emissions generated from barbecuing chickens have revealed many unsaturated hydrocarbons, a form of VOCs that is highly reactive in the photochemical process. The primary sources of these emissions were the produced from the cooking processes. For averaging $100 \mathrm{~kg}$ per day of cooked meat for 300 days per year, the estimated VOC emissions produced from a small barbecue chicken shopis roughly equivalent to running a typical car for $20,000 \mathrm{~km}$ per year.

Grease particles and aerosols can also be generated from certain cooking process. From ASHRAE 1375 final report, the results of the emission tests indicated that the wok had the largest total grease emission in the plume, $247 \mathrm{lb}$ grease $/ 1000 \mathrm{lb}$ food cooked, nearly a factor of two over the appliance with the second highest emission, the solid fuel broiler at $142 \mathrm{lb}$ grease/1000 lb food cooked. The conveyor broiler had $50.2 \mathrm{lb}$ grease/1000 lb food cooked whereas the other appliances were less than 14. The total grease emissions in the exhaust duct were less than the values in the plume primarily because the plume mass emissions are often dominated by particles larger than $10 \mu \mathrm{m}$ in size. These large particles rarely make it into the exhaust duct to be sampled by the instrumentation located there. Thus the total grease mass emissions in the exhaust duct ranged from $72.5 \mathrm{lb}$ grease $/ 1000 \mathrm{lb}$ food product for the solid fuel broiler to $2.64 \mathrm{lb}$ grease $/ 1000 \mathrm{lb}$ food product for the conveyor pizza oven[9].

Particles larger than $10 \mu \mathrm{m}$ often dominated the total mass effluent in the plume whereas grease vapor dominated the effluent in the exhaust. Much of the grease mass emission was found to be in the vapor phase or associated with particles smaller than $1 \mu \mathrm{m}$ in size [7][9]. From the previous investigation, the condensable vapor grease produced from cooking operations are measured from U.S Environmental Protection Agency (EPA) method 5 [10] and method 202 [11] to determine the condensable particulate emission from inside and outside the plenum location.

Now days, many of the kitchen hood are equipped with mechanical grease filter such as cyclonic KSA and baffles plate to filter the grease emission from cooking process. During cooking operation, the efficiency of mechanical grease filter or extractor only efficient to capture particulate size larger than $10 \mu \mathrm{m}[1]$, [7], [9]. In real situation, the particulate size range from $0.5 \mu \mathrm{m}$ and up to $20 \mu \mathrm{m}$ [9] depends on the cooking styles. None of the mechanical filters is effective in capturing particles less than $2.5 \mu \mathrm{m}$ [1]. The cyclonic filter traps at least twice the amount of grease compared to the best baffle filter in the particle range from 2.5 to $10 \mu \mathrm{m}$ at the exhaust airflow $274 \mathrm{cfm} / \mathrm{ft}(424 \mathrm{~L} /[\mathrm{s} \cdot \mathrm{m}])$ and three times more grease at $144 \mathrm{cfm} / \mathrm{ft}(223 \mathrm{~L} /[\mathrm{s} \cdot \mathrm{m}])$ and $196 \mathrm{cfm} / \mathrm{ft}(303 \mathrm{~L} /[\mathrm{s} \cdot \mathrm{m}])$ exhaust airflow. The previous study reported the filtration efficiency for all filters increases with the airflow as a result of higher pressure drop across the filter[1].

To increase the emission filtration efficiency, the kitchen hood is equipped with the combination of the mechanical grease filter and water-mist spray. It has been revealed the cold-mist sprays are able to capture the small grease particulate size by increasing the diameter of grease particles from the temperature drop and grease vapor solidified during the cold-mist process [12], [13]. Until now, there is no publication and report documented to reveal and prove the result even though it is possible in theory.

\section{METHODOLOGY}

To study the grease filtration efficiency by the water-mist recirculation system, the experimental parameter was based on Halton U.S and Halton Europe kitchen hood operating conditions. For the installation of the kitchen hood ventilation system was based on ASTM 2519-05 and UL1046. The grease machine was selected as cooking load in this study for consistency and the standard operating condition comply with UL 1046 standard. Table 1 shows the experimental configuration selected to perform this study. 
TABLE 1. EXPERIMENT CONFIGURATION

\begin{tabular}{|l|l|}
\hline Operating pressure & 1.67 bar \\
\hline Spray nozzle integration & 3 nozzles per row \\
\hline Nozzle type & $1 / 8$ KSJB 0.5 flat fan spray \\
\hline Kitchen & Scaled KHV (1:2) \\
\hline Water quality & Fresh water and cycled wastewater (WW2 to WW8) \\
\hline Water-mist per cycle & 30 minutes \\
\hline
\end{tabular}

\section{A. Experimental Setup}

The experimental investigation was performed from grease loading by utilizing the grease machine and scaled (1:2) kitchen hood canopies as in Fig. 1. The grease machine was built based on a design detailed in UL 1046 (Grease filters for exhaust ducts) purpose for loading primary filters and water mist with grease for data consistency and continuous measurement on grease removal efficiency testing.

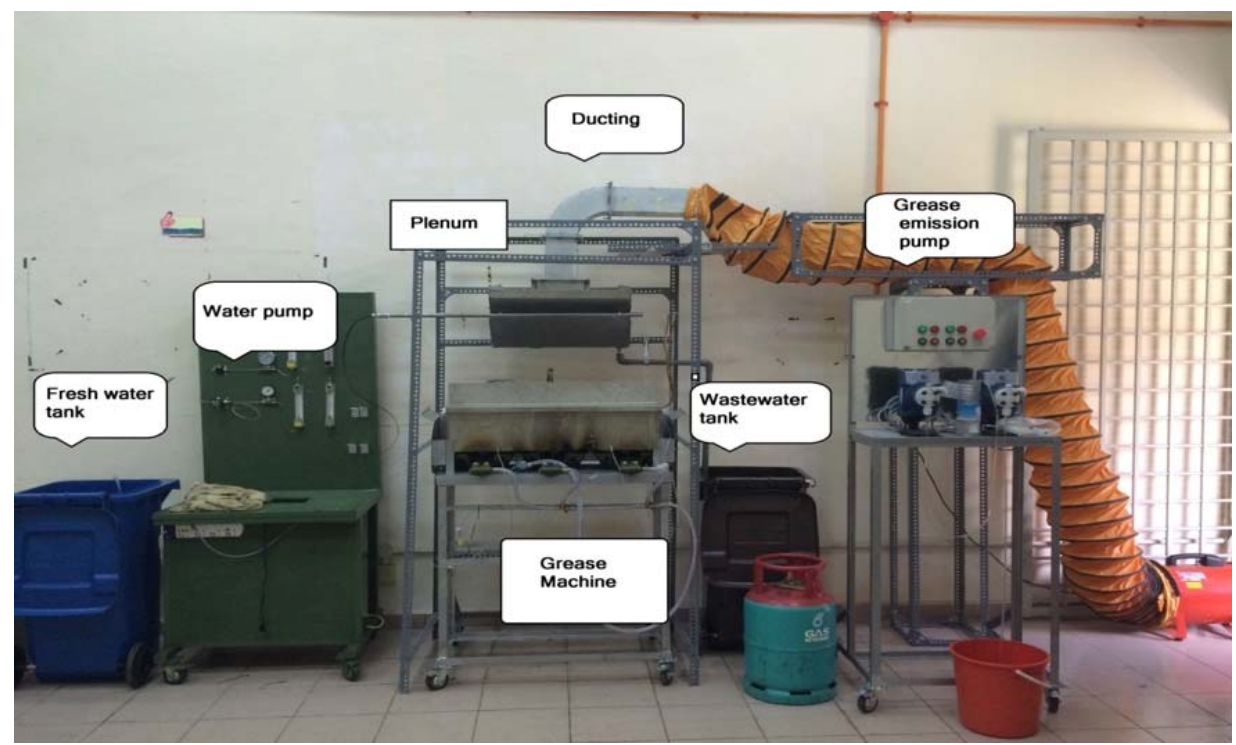

Fig. 1Experimental setup

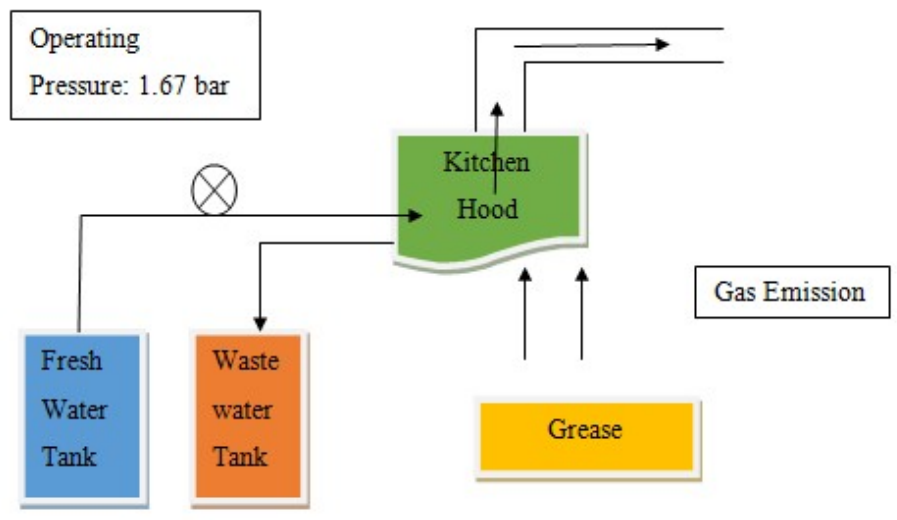

Fig. 2Schematic diagram of water-mist recirculation

A schematic diagram of the test setup is shown in Fig. 2. The inlet pressure of working fluid (fresh water\& recycled water WW2-WW8) was set to 1.67 bar at water-mist spray flow rate $0.29 \mathrm{l} / \mathrm{min}$ per nozzle. The grease loading system includes a chamber (vapor box), burner, dossing pump, oil, and water. An oil and water flow rate was set to $10 \pm 0.5 \mathrm{ml} / \mathrm{min}$ and $24.5 \pm 0.5 \mathrm{ml} / \mathrm{min}$ using 2 dossing pump. Oils and water weight are recorded using a digital scale before and after the test to assure the correct amounts of oil and water loaded during the test. A heat source was produced from 3 burner placed at the bottom of the vapor box and was maintained heated at range of $385 \pm 14{ }^{\circ} \mathrm{C}$. The temperature of the heat source was determined by 2 chromal-alumel ( $k$-type) thermocouple placed in the vapor box. 
The exhaust fan and burner was activated at first 12 minutes to stabilize the flow rate and heat source temperature. The oils and water was loaded right after the temperature stable at range $377^{\circ} \mathrm{C}$ to $399^{\circ} \mathrm{C}$. The test for temperature of the grease loaded was set to 30 minutes sampling time. 30 minutes after sampling, the oils, water, and burner was stop immediately supply to the system.

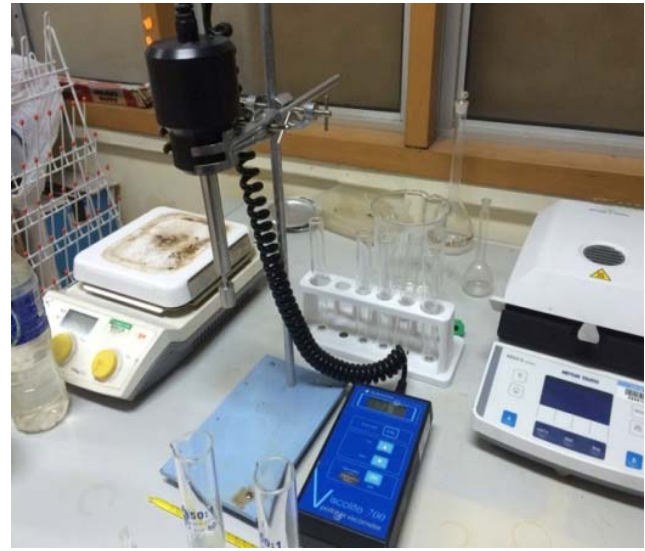

Fig. 3Viscometer

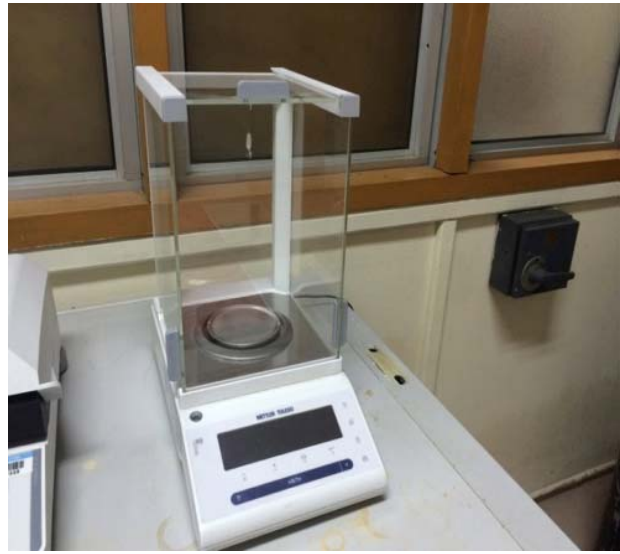

Fig. 4Analytical balance

The wastewater from water-mist waste samples was collected inside the strainer to determine the fluid properties. This samples then was delivered to the laboratory to measure the mass and viscosity of the fluids. Viscometer was used to measure the viscosity of the wastewater as in Fig. 3. Mass of the wastewater was measured using analytical balance as in Fig. 4. This two measurement will provide us the data to determine the density of the wastewater samples.

TABLE 2. WATER-MIST CYCLE(S) PROPERTIES

\begin{tabular}{|c|c|c|c|c|c|}
\hline $\begin{array}{l}\text { Water-mist } \\
\text { type (cycle) }\end{array}$ & Mass (g) & $\begin{array}{l}\text { Volume } \\
\left(\mathrm{cm}^{3}\right)\end{array}$ & $\begin{array}{l}\text { Density } \\
\left(\mathrm{g} / \mathbf{c m}^{3}\right)\end{array}$ & $\begin{array}{l}\text { Viscosity } \\
\text { (cP) }\end{array}$ & $\begin{array}{c}\text { Molar mass } \\
(\mathrm{kg} / \mathrm{mol})\end{array}$ \\
\hline Fresh water & 24.9878 & 25.063 & 0.997 & 0.7 & 18.02 \\
\hline WW2 & 25.2122 & 25.063 & 1.005 & 0.8 & 20.28 \\
\hline WW4 & 25.4366 & 25.063 & 1.013 & 0.9 & 22.54 \\
\hline WW6 & 25.6610 & 25.063 & 1.021 & 1.0 & 24.80 \\
\hline WW8 & 25.8854 & 25.063 & 1.029 & 1.1 & 27.06 \\
\hline
\end{tabular}

Before performing a simulation work, some of the fluid properties details need to be calculated. Table 2 shows the results of wastewater from water-mist properties. The density and viscosity slightly increase cycle by cycle which shows the others wastewater properties are also increase. The molar mass of wastewater increased as the density and viscosity increased.

\section{B. Simulation Setup}

In this research, the nozzle geometry was base on $1 / 8 \mathrm{KJSB} 0.5$ with flat fan spray type. The nozzle geometry was designed using SolidWorks. Then, the nozzle design was exported to ANSYS software for simulation analysis. The descriptions and the boundary condition used in this simulation analysis as in Table 3 .

TABle 3. Simulation Configuration

\begin{tabular}{|c|c|}
\hline Descriptions & Boundary Condition \\
\hline Analysis type & Steady state \\
\hline Nozzle inlet pressure & $1.67 \mathrm{bar}$ \\
\hline Nozzle outlet pressure (opening) & $1 \mathrm{~atm}$ \\
\hline Turbulence Intensity & $5 \%$ \\
\hline Turbulence Model & $k$-epsilon \\
\hline Working Fluid & Water and wastewater \\
\hline Walls & Smooth wall \\
\hline
\end{tabular}




\section{RESUlT AND DISCUSSION}

This research aims to simulate the spray characteristics of the water-mist recirculation system base on water quality from experimental data. There are 4 different types cycle of wastewater, which areWW2, WW4, WW6 and WW8 where WW2 is for water-mist at cycle 2 of recirculation and WW8 is for water-mist at cycle 8 of recirculation.

\section{Actual Water-mist Spray Velocity}

The water-mist spray outlet velocity was obtains using Bernoulli's equation. Bernoulli's Eqn. 1 and Eqn. 2 was applied to determine the water-mist spray velocity at nozzle outlet, $v_{2}$. The spray velocity for each watermist spray activation cycle may differ due to fluid density.

$$
\begin{gathered}
P_{1}+\frac{1}{2} \rho v_{1}^{2}+\rho g h_{1}=P_{2}+\frac{1}{2} \rho v_{2}^{2}+\rho g h_{2} \\
v_{2}=\sqrt{P_{1}-P_{2}+\frac{1}{2} \rho v_{2}^{2}-\frac{1}{2} \rho+\rho g\left(h_{1}-h_{2}\right)}
\end{gathered}
$$

Eqn. 1

Eqn. 2

The outlet velocity of the nozzle spray, $v_{2}$ was obtained for a comparison with the simulation results

TABle 4. ACtUAL SPRAY VELOCITY

\begin{tabular}{|l|l|l|l|l|l|l|}
\hline Water-mist spray & Freshwater & WW2 & WW4 & WW6 & WW8 \\
\hline Position & Distance Y (m) & \multicolumn{5}{|c|}{ Spray velocity (m/s) } \\
\hline Inlet & 0.068 & 0.390 & 0.389 & 0.387 & 0.385 & 0.384 \\
\hline Outlet & 0.052 & 10.937 & 10.895 & 10.852 & 10.809 & 10.767 \\
\hline
\end{tabular}

Table 4shows the actual spray velocity results obtained from experiment and calculation above. There are two positions, which areat nozzle inlet at $0.068 \mathrm{~m}$ height and at nozzle outlet at $0.052 \mathrm{~m}$ height. The distance between nozzle inlet and outlet is $16 \mathrm{~mm}$. The inlet water-mist pressure is set at 1.67 baratfluid velocity 0.39 $\mathrm{m} / \mathrm{s}$. The spray velocity at nozzle inlet and outlet decreased as the number of cycle increased.

\section{Water-mist Spray Velocity From Simulation}

In this simulation, graph pattern for all water and wastewaters are same but slightly different in small margin. Thesprayvelocity at nozzle inletwas $0.391 \mathrm{~m} / \mathrm{s}$ and growing steadily until reach the bottleneck of nozzle. The spray velocity increased drastically as the water flowing through orifice, $0.5 \mathrm{~mm}$ and slowing down as the water spread into the domain or in actual situation is spread into the plenum of kitchen hood.

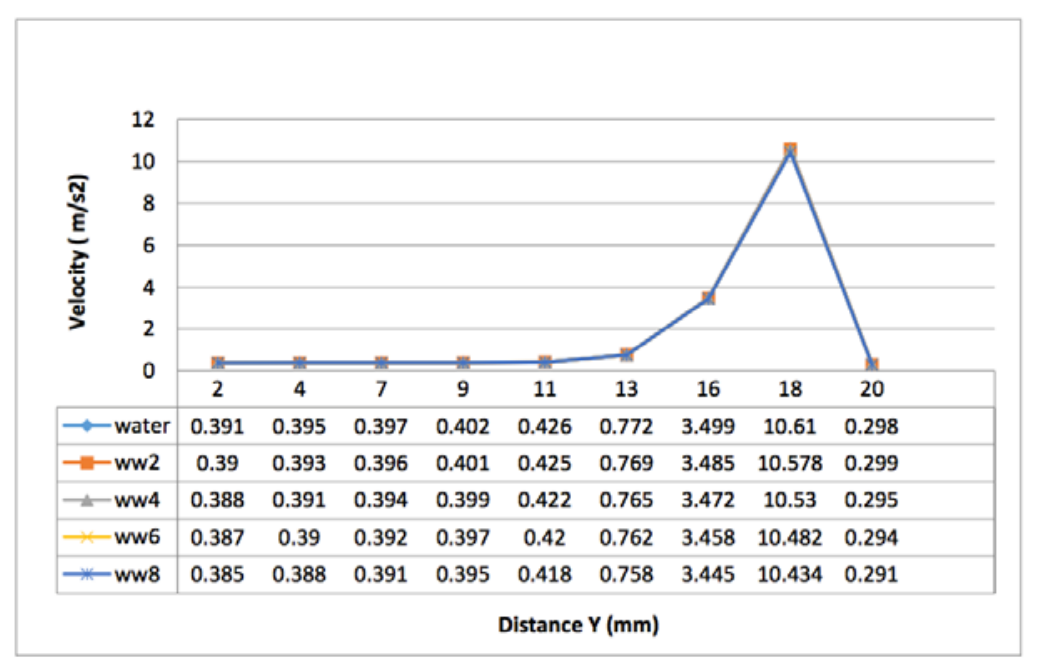

Fig. 5Spray velocity at distance $Y$ for each water-mist spray cycle.

For WW2, the flow pattern shows the same but the overall velocity shows decreasing as the number of cycle of wastewater increase. From the table above, the result for WW2 at distance $2 \mathrm{~mm}$ (inlet) the velocity is $0.39 \mathrm{~m} / \mathrm{s}$, which is $0.01 \mathrm{~m} / \mathrm{s}$ lower than fresh water. This goes to all other wastewaters, the velocity decrease as the number of cycle of wastewater increases. 
The wastewater contains $99 \%$ of water and $1 \%$ ofFOG. The FOG contains in the wastewater increased as the number of cycle increased. Thus, the viscosity and density of the fluids increased and more viscous as the number of cycle increased.

The highest velocity was recorded at velocity of $10.61 \mathrm{~m} / \mathrm{s}$, at distance $18 \mathrm{~mm}$ forfresh water. The spray velocity decreasing as the flow reached at distance $18 \mathrm{~mm}$ where the spray enters and disperse into the air. The lowest spray velocity was recorded at velocityof $0.291 \mathrm{~m} / \mathrm{s}$ at distance $20 \mathrm{~mm}$ for WW8 as in Fig. 5

\section{E. Water-mist Spray Pressure From Simulation}

Fig. 6 shows the fluids flow steadily from distance $2 \mathrm{~mm}$ to $13 \mathrm{~mm}$. The pressure started to drop at point 16 $\mathrm{mm}$ and drastically drop afterward. The pressure was drop at point $16 \mathrm{~mm}$ due to passage that passes through bottleneck of nozzle.

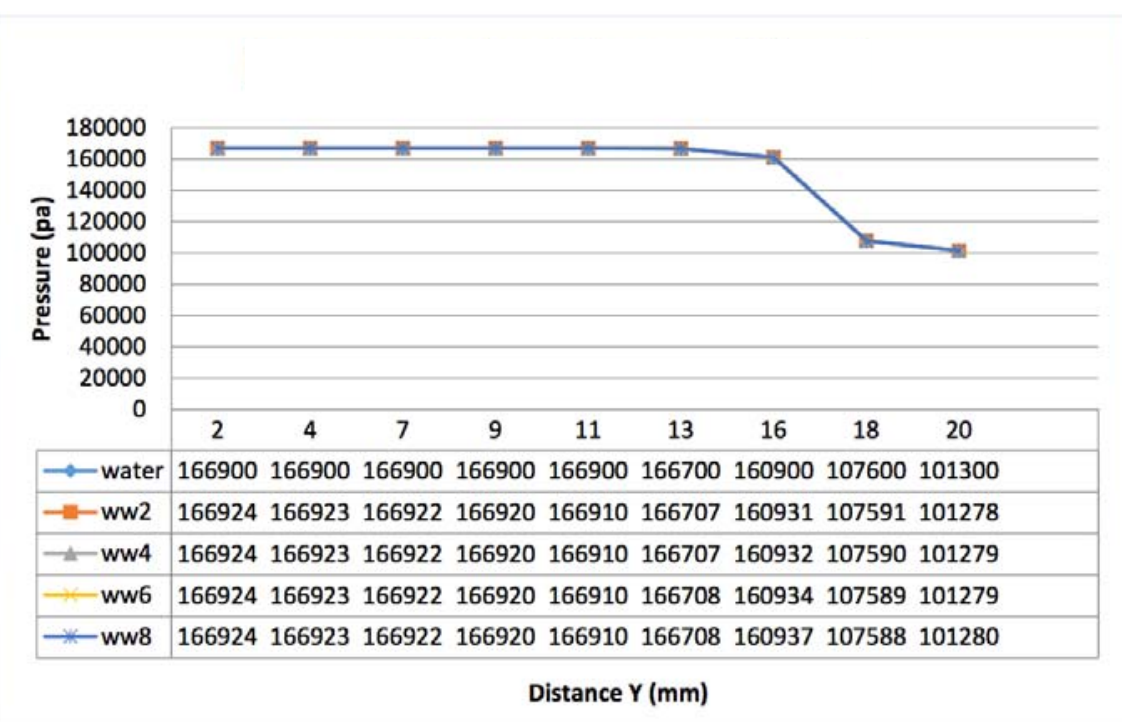

Fig. 6Spray pressure at distance $\mathrm{Y}$ for each water-mist spray cycle

The inlet pressure for fresh water is 1.67 bar and it is similar for other cycles. The recorded pressure values almost same but there are slightly different at point $13 \mathrm{~mm}$ between cycles of WW4 and WW6. The water-mist spray pressure increased between WW4 and WW6 and at start to drop at point $18 \mathrm{~mm}$. This is because the WW6 is denser and more viscous than WW4. Furthermore, to get better understanding, the data at point $16 \mathrm{~mm}$ shown increases of pressure flow between WW4, WW6 and WW8. As the number of cycle of wastewater increased the pressure generated from the nozzle outlet decreased.

\section{F. Absolute Error, $E_{A B S}$ of Spray Velocity Between Actual and Simulation}

Table 5below shows the overall absolute error, $E_{A B S}$ of water-mist spray velocity at nozzle inlet and outlet between experimental and simulation.

TABLE 5. OVERALL ABSOLUTE ERROR OF WATER-MIST SPRAY VELOCITY.

\begin{tabular}{|l|l|r|r|r|r|r|}
\hline Nozzle & Description & Fresh & WW2 & WW4 & \multicolumn{1}{l}{ WW6 } & WW8 \\
\hline \multirow{5}{*}{ Inlet } & Actual velocity, $v_{\exp }(\mathrm{m} / \mathrm{s})$ & 0.390 & 0.389 & 0.387 & 0.385 & 0.384 \\
\cline { 2 - 7 } & CFD velocity, $v_{C F D}(\mathrm{~m} / \mathrm{s})$ & 0.390 & 0.389 & 0.387 & 0.385 & 0.384 \\
\cline { 2 - 7 } & {$\left[v_{\exp }-v_{C F D}\right]$} & 0 & 0 & 0 & 0 & 0 \\
\cline { 2 - 7 } & $E_{A B S}(\%)$ & 0 & 0 & 0 & 0 & 0 \\
\hline \multirow{5}{*}{ Outlet } & Actual velocity, $v_{\exp }(\mathrm{m} / \mathrm{s})$ & 10.937 & 10.895 & 10.852 & 10.809 & 10.767 \\
\cline { 2 - 7 } & CFD velocity, $v_{C F D}(\mathrm{~m} / \mathrm{s}$ & 10.610 & 10.578 & 10.530 & 10.482 & 10.434 \\
\cline { 2 - 7 } & {$\left[v_{\exp }-v_{C F D}\right]$} & 0.327 & 0.317 & 0.322 & 0.327 & 0.333 \\
\cline { 2 - 7 } & $E_{A B S}(\%)$ & 2.990 & 2.910 & 2.967 & 3.025 & 3.093 \\
\hline
\end{tabular}


At nozzle inlet, the parameters (spray velocity) was set at same inlet pressure, 1.67 bar. The inlet velocity between simulation and actual at each cycle are same resulting there are no absolute difference. The actual and simulation spray velocity are vary at nozzle outlet. The actual outlet velocity for fresh water recorded is 10.937 $\mathrm{m} / \mathrm{s}$ and for the simulation the outlet velocity is $10.61 \mathrm{~m} / \mathrm{s}$. The percentage of absolute error for the fresh water is $2.990 \%$. At nozzle outlet, the actual velocity is higher than simulation results as shown inTable 5 . The highest absolute erroris $3.093 \%$ was recorded at the nozzle outlet at cycle WW8.

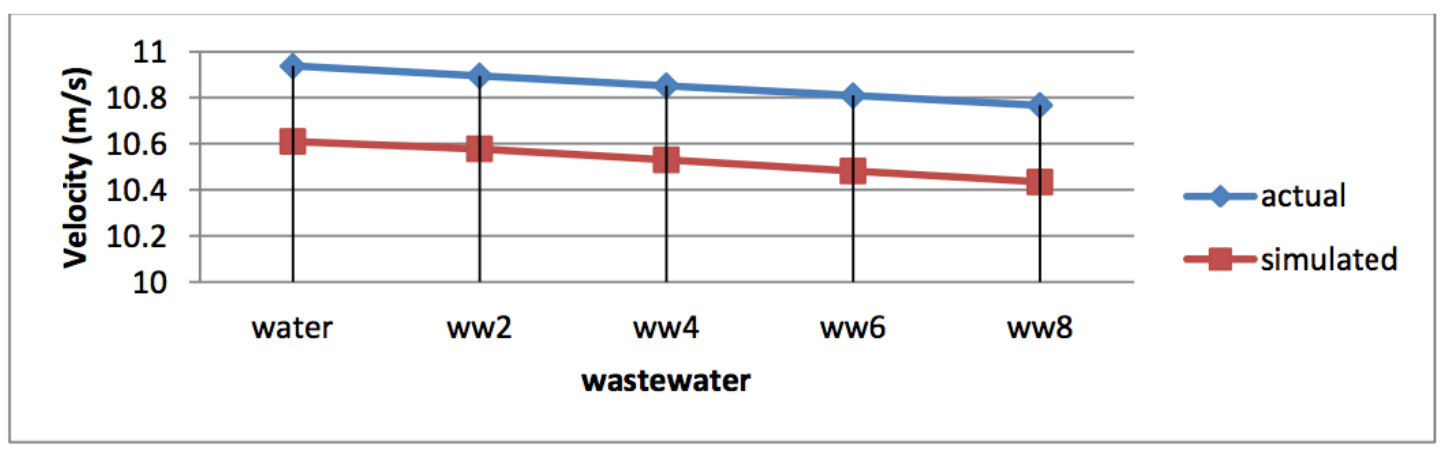

Fig. 7Nozzle outlet velocity between actual and simulation for each cycle.

The highest percentage of absolute error is at WW8, 3.093\%, followed by WW6, fresh water, WW4 and WW2 which is $3.025 \%, 2.990 \%, 2.967 \%$ and $2.910 \%$ respectively. As a conclusion, the percentages of absolute error between actual and simulation nozzle velocity for all cycles are less than $5 \%$.

\section{G. Percentage of Velocity Drop}

The efficiency of the water-mist spray from the recirculation system dropped by water-mist activation time (number of cycles used). There is a limitation that the recirculation system efficient to filter the grease emissions and to control the hood and ducting temperature at certain percentage of spray velocity drop. It is important to us to predict how long the wasted water by water-mist spray can be used as water-mist spray efficiently.

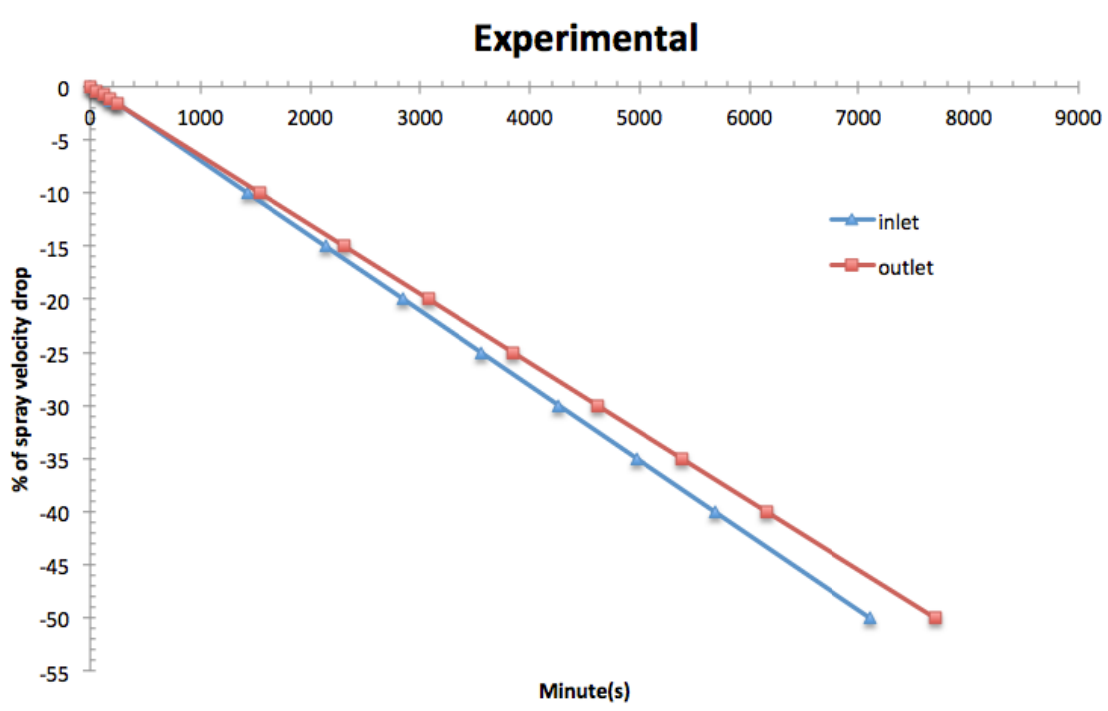

Fig. 8Percentage of spray velocity drop by activation time

The percentage of spray velocity drop is determined from nozzle inlet and nozzle outlet velocity data through out the experimental and simulation results. Predictions of percentage of spray velocity drop are determined through out calculation (interpolation) from experimental and simulation data. Error! Reference source not found. shows the prediction of spray velocity up to $50 \%$ of the percentage drop.

Base from nozzle inlet spray velocity data, the spray velocity is predicted to drop up to $10 \%$ at 1428 minutes of water-mist activation time. The nozzle outlet spray velocity recorded almost similar with inlet velocity where the spray velocity is predicted to drop at $10 \%$ at 1539 minute of water-mist activation time. From this figure, per cycle of fresh water ( 30 minutes) can be utilized at an average 24 hours of water-mist activation 
TABLE 6. WATER-MIST OPERATING COST COMPARISON.

\begin{tabular}{|l|r|r|r|r|}
\cline { 2 - 5 } \multicolumn{1}{c|}{} & \multicolumn{2}{c|}{ Water-mist Hood Design 1 } & \multicolumn{2}{c|}{ Water-mist Hood Design 2 } \\
\cline { 2 - 5 } \multicolumn{1}{c|}{} & \multicolumn{1}{c|}{ Current } & Recirculation & \multicolumn{1}{c|}{ Current } & Recirculation \\
\hline Tariff (Eur/m3) & 1.60 & 1.60 & 3.01 & 3.01 \\
\hline Nb of nozzle (water-mist) & 6 & 6 & 6 & 6 \\
\hline Operating pressure (bar) & 2.76 & 2.76 & 1.67 & 1.67 \\
\hline $\begin{array}{l}\text { Water flow per nozzle } \\
\text { (1/min) }\end{array}$ & 0.38 & 0.38 & 0.29 & 0.29 \\
\hline $\begin{array}{l}\text { Water flow at nozzle } \\
\text { (1/min) }\end{array}$ & 2.28 & 2.28 & 1.74 & 1.74 \\
\hline Operating time hours/day & 12 & 12 & 12 & 12 \\
\hline Fresh water (1/day) & 1641.6 & 68.40 & 1252.80 & 52.20 \\
\hline Fresh water (1/year) & 599184 & 24966 & 457272 & 19053 \\
\hline Fresh water (m3/year) & 599.184 & 24.966 & 457.272 & 19.053 \\
\hline Total water cost (eur/year) & 958.69 & 39.95 & 1376.39 & 57.35 \\
\hline $\begin{array}{l}\text { Total water cost } \\
\text { (eur/month) }\end{array}$ & 79.89 & 3.33 & 114.70 & 4.78 \\
\hline Saving /year (eur/year) & 0.00 & 918.74 & 0.00 & 1319.04 \\
\hline
\end{tabular}

Now, lets assume the maximum velocity drop allowed is $10 \%$ from current operating velocity and the other parameters are as in Error! Reference source not found.. To estimate the operating cost, the recirculation system will be compared with current operating condition, which is recommended by manufacturer.

It is clearly shows us that, under these conditions, the water-mist hood represent an operating cost for the user. The recirculation water-mist system will reduce the water consumption by 918.74 euro per year and 1319.04 euro per year for Water-mist Hood design 1 and 2.

\section{CONCLUSION}

The water-mist recirculation system was tested experimentally by comparing the spray velocity between actual and simulation. A simulation work has been done to determine the effects of nozzle spray characteristic by wasted water-mist water spray for each cycle. Both experimental and simulation analysis are important to predict the life cycle of wasted water-mist water, and water consumption along the water-mist activation.

Based on the study using scale KHV system, the water-mist recirculation system has great potential and improvement to the current system operation. By adopting the recirculation system to current water-mist kitchen hood, the operational cost was reduced. From the analysis, the user could save up to 1319.04 euro per year per hood length. It is $95.83 \%$ of water cost reduction for existing water-mist kitchen hood design 1 and 2 .

\section{ACKNOWLEDGMENT}

This research work was supported by Universiti Tun Hussein Onn Malaysia (FRGS Research Grant vot 1540) and Halton Foodservice (Malaysia) Sdn. Bhd.

\section{REFERENCES}

[1] A. Livchak, D. Schrock, M. Lehtimaki, and A. Taipale, "The Facts Mechanical Grease,” Am. Soc. Heating, Refrig. Air-Conditioning Eng. ASHRAE J., no. June, 2003.

[2] "NFPA 96: Standard for Ventilation Control and Fire Protection of Commercial Cooking Operations," NFPA Int., vol. MA 02269-9, no. USA, 2001.

[3] K. L. Abdullahi, J. M. Delgado-Saborit, and R. M. Harrison, "Emissions and indoor concentrations of particulate matter and its specific chemical components from cooking: A review,” Atmos. Environ., vol. 71, pp. 260-294, 2013.

[4] Y. Zhao, A. Li, R. Gao, P. Tao, and J. Shen, "Measurement of temperature, relative humidity and concentrations of $\mathrm{CO}, \mathrm{CO} 2$ and TVOC during cooking typical Chinese dishes," Energy Build., vol. 69, pp. 544-561, 2014.

[5] M. P. D. William D. Gerstler, Thomas H. Kuehn, David Y. H. Pui, James W. Ramsey, "Identification and Characterization of Effluents from Various Cooking Appliances and Processes as Related To Optimum Design of Kitchen Ventilation System," Am. Soc. Heating, Refrig. Air-Conditioning Eng. ASHRAE, vol. 2, no. ASHRAE 745-RP, p. Phase 1, Final Report, 2011.

[6] C. Stephane, "Waterwash \& Watermist Optimized Control Cabinet with Recirculation System\& Detergent Optimisation (Pre-study)," Lab Meas. Halt. R\&D Bethune, Fr., 2013. 
[7] J.-B. Lee, K.-H. Kim, H.-J. Kim, S.-J. Cho, K. Jung, and S.-D. Kim, "Emission rate of particulate matter and its removal efficiency by precipitators in under-fired charbroiling restaurants.," ScientificWorldJournal., vol. 11, pp. 1077-1088, 2011.

[8] W. et Al., "Control of fine particulate (PM2.5) emissions from restaurant operations," J air waste mgt assoc, vol. 49, no. Sept pp, pp. PM95-99, 1999.

[9] T. H. Kuehn, B. a Olson, J. W. Ramsey, J. M. Rocklage, and D. Gross, "Characterization of effluents from additional cooking appliances," Ashrae, 2007.

[10] "Method 5: Determining of particulate matter emission from stationary sources," U.S. Environ. Prot. Agency, no. HTTP://WWW.ECFR.GOV/CGI-BIN/TEXT-

IDX?SID=C7836E6FF67E5AD001BCB19CCFD99C1A\&NODE=40:8.0.1.1.1\&RGN=DIV5\#40:8.0.1.1.1.0.1.1.3, pp. 1-41.

[11] "Method 202: Dry impinger method for determining condensable particulate emissions from stationay sources," U.S. Environ. Prot. Agency

no. HTTP://WWW.ECFR.GOV/CGI-BIN/TEXTIDX?SID=ADEABEEA3BEAF99D897C60E040069E69\&NODE=40:2.0.1.1.2\&RGN=DIV5\#40:2.0.1.1.2.23.11.5.30, pp. 1-25.

[12] N. Asmuin, M. F. Sies, M. K. Hassan, M. R. Pairan, N. a. Nor Salim, and H. Zakaria, "Simulation of Water Mist Spray for Commercial Kitchen Ventilation (CKV) System Using Ansys-CFD,” Appl. Mech. Mater., vol. 660, pp. 704-708, 2014.

[13] Halton Foodservice, "Very specific cooking appliance calls for very specific solution," https://www.halton.com/dh/AQAzhgIQISbMvdtHv65zq1Jeyn0easNK10I0m5SAN5cVr597ti0o7EEeNMbc8pItz7vwqfq0uZ0ZHBsqgf18YGTkPmgqIrJZwSmdplHHE2UIog5mB2uqScg6oCC0Q/Halton-FS-HaltonforJosper-uk1312.pdf.

\section{AUTHOR PROFILE}

Nor Adrian Nor Salim is Postgraduate student (Ph.D) and Researcher of Industrial Environment Engineering Research Group (IERG), Centre for Energy \& Industrial Environment Studies (CEIES), Universiti Tun Hussein Onn Malaysia (UTHM).

Norzelawati Asmuinis Associate Professor and Researcher of Industrial Environment Engineering Research Group (IERG), Centre for Energy \& Industrial Environment Studies (CEIES), Universiti Tun Hussein Onn Malaysia (UTHM). 